\title{
Healthcare in the United States Unnecessary Procedures, Lawsuits, and Skyrocketing Costs
}

\author{
Jason Mehta1, Lauren Tribble ${ }^{2}$, Jawahar L. Mehta ${ }^{3 *}$
}

${ }^{1}$ Department of Sate, United States Government

${ }^{2}$ Counselor to the Senator Berne Sanders (I-VT)

${ }^{3}$ Division of Cardiology, University of Arkansas for Medical Sciences, Little Rock, USA

The United States spends significantly more per capita on healthcare than any other country, roughly $18 \%$ of our GDP or more than $\$ 8,000$ per person per year [1]. This fact weighs heavily on our competitiveness in business, as we have reached the point where many American companies pay as much, or more, to provide heath insurance to their workers as to make their products. General Motors, for example, pays more for healthcare of its employees than it does for steel [2]. Perhaps even more concerning is that the United States has the highest healthcare spending growth rate in the world, a fact which does not bode well for our future [3] The nonpartisan Congressional Budget Office, in fact, estimates that healthcare spending will almost double to $31 \%$ of our GDP - almost one third of our economy-by 2035 if the present rate of growth in healthcare cost continues [4]. Despite this expenditure, the United States does not provide better healthcare to its people than other developed countries. Fifty million Americans are uninsured [5] another 25 million are underinsured [6] ,and the United States consistently ranks below most other developed nations in such important metrics as patient safety and outcome [7]. One has to ask where all this money is going. Why are we spending so much and get so little in exchange?

There are a number of nuanced answers to this problem, but they all come back to the same unavoidable reality: Our healthcare system is driven by industry's desire for profit and patients' desire for more, though not necessarily better, care. Consider who is in the room when decisions are made about appropriate treatment of the patient. Physicians have every incentive to provide the most technologically advanced care in order to bolster their income, please their patients, and avoid litigation. They are encouraged to do so by hospital administrators, who are concerned with their own salaries and with the hospital's bottom line, and drug companies, which aggressively market their wares. Patients, who are thinking of life and death, are often afraid and lack the know-how to question the decisions being made for them. They have every incentive to accept the treatment offered, especially given that they rarely face financial consequences until after the fact. It is no wonder, then, that costs are spiraling. No one who cares about costs is in the room to put the brakes on.

To give just one example of how these perverse incentives can get out of hand, consider the case of cardiologist Dr. Mark Midei. Dr. Midei was especially aggressive in encouraging his patients to get stents in heir coronary arteries, and he received nothing but positive feedback for this approach [8]. Because he billed far more than most, Dr. Midei's employer considered him a rainmaker and rewarded him with high salary and prestige. The stent manufacturer, Abbott Laboratories, was of course thrilled with Dr. Midei, and over the years offered him millions of dollars in consulting fees and perks. These incentives had the intended effect; for example, on a single day in August 2008, Dr. Midei inserted 30 stents manufactured by Abbott Laboratories. After sending celebratory emails, Abbott representatives followed up two days later by spending over $\$ 2000$ on a barbecue dinner at Dr. Midei’s home.

One might expect pushback from the patients, as the unnecessary stents compromised their safety, but they were happy as well. Most were experiencing chest pain and afraid when they went to see Dr. Midei. They felt that by offering them a stent, Midei had taken their condition seriously and had helped them. Even after a 66-year-old patient found out that Dr. Midei had lied to her about the severity of her condition, she said "No one can ever tell me that I didn't need that stent. I feel he saved my life." Another gratified patient said, "[h]e put two stents in, and almost immediately, I felt relief."

Ultimately, Dr. Midei pushed the limits by actually lying frequently to his patients, purposely misreading coronary angiograms to define the degree of narrowings in coronary arteries, and became ensnared in legal troubles. Dr. Midei's case may be extreme; however, the incentives in play in the Midei case are a common occurrence across the country.

In another case, Dr. John Mclean of Peninsula Regional Medical Center in Salisbury, Maryland, was charged on six counts of fraud relating to insurance claims for stents deemed to have been placed unnecessarily in numerous patients, as well as for ordering unnecessary tests and making false entries in patient medical records[9]. The hospital settled the case by paying $\$ 1.8$ million. Along the lines of Midei and Mclean, Dr Mehmood Patel, of Our Lady of Lourdes Hospital and Lafayette General Hospital in Louisiana, was convicted on 51 counts of billing private and government health insurers for unnecessary medical procedures and received a 10-year sentence [10].

It is easy to dismiss these cautionary tales as acts of a few rogue physicians, driven by greed. Yet, this is not the case. In part, we hear the same message from hospitals, from industry, and even from patients: Provide the best (read- the most expensive), high tech care that you can possibly justify, whether or not the expected outcomes give reason for the expense. Providers who do this are rewarded with high salaries, consulting opportunities from drug companies and device manufacturers, and at times with high patient satisfaction. Providers who miss out on these "easy money making opportunities" also face the possibility of lawsuits by patients who feel that more should have been

*Corresponding author: JL Mehta, MD, PhD Cardiovascular Division, UAMS Little Rock, AR 72212, Tel: 501-296-1426; E-mail: MehtaJL@UAMS.edu

Received September 09, 2011; Accepted September 11, 2011; Published September 13, 2011

Citation: Mehta J, Tribble L, Mehta JL (2011) Healthcare in the United States Unnecessary Procedures, Lawsuits, and Skyrocketing Costs. J Forensic Res S2:003. doi:10.4172/2157-7145.S2-003

Copyright: (c) 2011 Mehta J, et al. This is an open-access article distributed unde the terms of the Creative Commons Attribution License, which permits unrestricted use, distribution, and reproduction in any medium, provided the original author and source are credited. 
done. It is no wonder, then, that physicians respond by providing more and more and more, no matter how unnecessary, care.

Nor is the problem confined to unnecessary stents. It is well known that almost $10 \%$ of the stents occlude with 6 months and $10 \%$ or more occlude yearly after that, necessitating for the patient to return for repeat coronary angiogram and further stent implantation [1]. Patients who receive these metallic stent coated with drugs are almost always given additional drugs like clopidogrel which cost about $\$ 5$ a day for years to keep the stent open. Clopidogrel is now the third most expensive prescribed drug with 2010 sale of over $\$ 6.1$ billion with huge profit for the drug manufacturers [12]. Clopidogrel and similar drugs are almost always given with aspirin, and the two together cause significant numbers of patients to bleed excessively, at times requiring hospitalization and receive blood transfusion with its attendant cost and complications. It all started with a procedure that was not needed in the first place! Similarly, large numbers of pacemakers and defibrillators are being placed in thousands of patients every year for less than optimal indications- again requiring patients to return to their physicians for regular check up and battery change. Although here we have focused on the burgeoning cost of heart healthcare, a similar situation exists in almost all specialties of medicine.

One might ask whether this is really a problem at all. It is, after all, inherent to capitalism that employees will be rewarded for revenue generation. Perhaps we should put the burden on consumers-in this case, the patients- to look out for themselves and keep healthcare costs down.

While such an approach seems superficially appropriate, placing trust in patients to find the most appropriate and affordable health options is undesirable for many reasons. First, patients have asymmetric incomplete information. For the most part, patients are not in a position to assess what procedures or medications are or are not in their best interest. This is, of course, part of the reason why they go to the doctor in the first place. Second, because most patients, certainly those receiving the most expensive care, are insured, providers do not typically talk to patients about the price of the services they provide. It would be rare, for example, for a patient to ask how much a stent (or any other device) will cost before undergoing a procedure. It would be even rarer for that patient or his/her family members to decline to receive the procedure because of the price. Third, because patients are sick, they are often afraid and unable to act rationally. Even if a procedure is risky, expensive, and unlikely to improve their condition, an ailing patient might want to try it rather than do nothing. For these reasons, among others, the consumer, who would typically be the first line check on excess spending, does not serve that role in this market, and the feedback loop between the healthcare industry's greed and patients' fear continues unabated. On the other hand, physicians who have the data on the limited efficacy of these procedures often look the other way when it comes to making choice, in this case denying the patient an expensive procedure. After all- there are huge monetary benefits to the physician, the hospital and the corporate bosses.

So if the patient is not going to be the one asking for an optimal cost-effective care, then who will? We have already seen government bodies attempt to fix the problem. In September 2009, President Barack Obama urged Congress to get the situation under control. $\mathrm{He}$ remarked that"[o]ur collective failure to meet this challenge -- year after year, decade after decade -- has led us to the breaking point. .... If we do nothing to slow these skyrocketing costs, we will eventually be spending more on Medicare and Medicaid than on all other government programs combined"[13]. Yet the healthcare bill that came out of the effort by many people did very little to solve the problem because any attempt to interfere with the feedback loop between the physicians, hospitals, administrators, drug/device manufacturers and patients was met with intense skepticism and political backlash. Remember the politicians' catchy slogan "government ought not to get between you and your doctor?" Outsiders, it seems, are not welcome to interfere in any way with the doctor-patient relationship.

If patients cannot do it, and if government cannot regulate it, it seems the next best choice would be for change to come from the insurance industry and NGOs. Fifty years ago, this would have been easier, but in today's profit-driven environment, it would require a fundamental change in our nation's thinking. Physicians would have to turn down huge financial gain and do what is right; pharmaceutical companies and device manufacturers would have to stop offering "bribes" and looking at lower profit margins; hospitals which have become huge money making corporations would have to start rewarding doctors based on patient outcome and procedures prevented rather than the number of procedures performed and amount billed. Insurance companies and payers will have to become more vigilant. Players across the healthcare industry would have to begin to see themselves primarily as professionals rather than businessmen. Although this change will be difficult, it is necessary, and given the rate at which our costs are skyrocketing, the change may be forced upon us sooner rather than later. After all, we just cannot afford the cost of healthcare-related technology. The question is- do we have the national will to do it and do it soon?

\section{References}

1. National Health Expenditure Data, 2009

2. Ailing GM looks to scale back generous health benefits. June 23, 2005.

3. http://www.kff.org/insurance/snapshot/OECD042111.cfm

4. The Long-Term Outlook for Medicare, Medicaid, and Total Health Care Spending.

5. http://www.kff.org/uninsured/upload/7451-06.pdf

6. http://health.usnews.com/health-news/family-health/articles/2008/06/10/25 million-americans-are-underinsured

7. http://www.commonwealthfund.org/ /media/Files/Publications/Fund $\% 20$ Report/2010/Jun/1400_Davis_Mirror_Mirror_on_the_wall_2010.pdf

8. Dr. Mark Midei's License Revoked After Stent Scandal, http://baltimore cbslocal.com/2011/07/13/dr-mideis-license-revoked-after-stent-scandal/.

9. Hospital Pays $\$ 1.8$ Million to Settle Unnecessary-Stenting Case.

10. Cardiologist Gets 10 Years for Performing Unnecessary Intervention

11. Ong AT, Hoye A, Aoki J, van Mieghem CA, Rodriguez Granillo GA, et al (2005) Thirty-day incidence and six-month clinical outcome of thrombotic stent occlusion after bare-metal, sirolimus, or paclitaxel stent implantation. J Am Coll Cardiol 45: 947-953.

12. The 10 Most Prescribed Drugs, http://www.webmd.com/news/20110420/the10-most-prescribed-drugs

13. Remarks by the President to a Joint Session of Congress on Health Care, September 9, 2009, http://www.whitehouse.gov/the press office/remarks-bythe-president-to-a-joint-session-of-congress-on-health-care/. 